\title{
Los civiles como víctimas de la guerra y de la propaganda. El ejemplo de la Guerra Civil Española (1936-1939)
}

\author{
Concha Langa Nuño \\ Universidad de Sevilla
}

\begin{abstract}
En las siguientes páginas se hace una aproximación al tema de la propaganda. Este es uno de los fenómenos de mayor interés en la centuria que ahora se cierra. Materia ilimitada e inagotable, ha alcanzado cumbres de especial interés. Una de ellas se sitúa en la Guerra Civil española. Dentro de su variedad, y a modo de aproximación a tan rico tema, hemos elegido la instrumentalización de la población civil como arma. La elección responde a varios aspectos. En instrumentalización de la población civil como arma. La elección responde a varios aspectos. En
primer lugar, porque de dicha propaganda se han estudiado más sus aspectos políticos atendiéndose menos este tema. En segundo, porque el ejemplo de la conculcación de derechos de la población civil sigue presente en nuestros días en los medios de información, y no está de más recordar que no se trata de un fenómeno reciente al calor de los nuevos tiempos. Para ello, hemos analizado diferente material y aportado varios ejemplos que evidencian los manejos de la propaganda totalitaria.

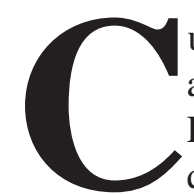

uando hoy contemplamos y leemos en los medios de información nos asaltan las imágenes de distintas guerras en lugares remotos o cercanos. De las muchas visiones terribles que nos acompañan a diario y con las que hemos llegado a convivir con naturalidad existe una que sigue provocando nuestra respuesta; los ataques a la población civil. Las imágenes de niños heridos o de enormes masas de gente huyendo de sus casas que nos llegan del otro lado del televisor o del periódico apelan a nuestros sentimientos de solidaridad sin ninguna duda. No está de más recordar que esta realidad universal es de sobra conocida por los que hacen las guerras $\mathrm{y}$, sobre todo, por los que las instrumentalizan. Y más, desde comienzos del siglo XX, el siglo de la "informa-

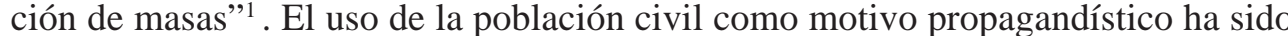
uno de los que más éxito ha tenido en nuestra centuria y sigue siendo usado en
\end{abstract}

Como, la Primera Guerra Mundial marcó un estadio culminante en el proceso que ocasionó la pérdida de credibilidad de los medios de información. Sin embargo su uso se mantuvo y perfeccionó en el período de entreguerras y en la Segunda Guerra Mundial.Vid. PIZARROSO QUINTERO, Alejandro: Historia de la Propaganda. Notas para un estudio de la propaganda política y de guerra. Madrid, Eudema, 1990. 
el presente de modo descarado. Y ello a pesar de que el año pasado vio la celebración del 50 aniversario de la Declaración Universal de los Derechos del Hombre.

Sirvan las siguientes palabras como una aproximación al estudio de la propaganda de nuestro siglo, centrándonos en el estudio de uno de los elementos más habituales en ella. Al mismo tiempo, puede relevar datos sobre el uso del fenómeno propagandístico en nuestra guerra civil, momento en el que alcanzó especial interés por su desarrollo espectacular, dentro y fuera de nuestras fronteras, imbuida en el contexto de la Europa de entreguerras.

La Guerra Civil de 1936 fue para los españoles de toda índole la mayor de las tragedias posibles; de igual modo, en el exterior, su evolución se siguió de forma apasionada. La carga ideológica de los dos bandos en litigio y de la Europa de entreguerras contribuyeron a ello. La necesidad de ayuda extranjera hizo que tanto el gobierno republicano como los alzados desplegasen campañas de propaganda para atraer las simpatías internacionales. Ambos se mostraron como víctimas y esgrimieron razones para apoyar sus actos. Mientras que los republicanos reivindicaron su legitimidad política atacada por un grupo de militares y núcleos conservadores y fascistas, éstos argumentaron los desmanes del gobierno del Frente Popular y de las fuerzas de "izquierdas" para lanzarse a la salvación de España. Por supuesto, los padecimientos de la población civil y el no respeto de los derechos humanos pasaron a ser el centro de argumentos de todo tipo.

En esa situación, la propaganda y su control se convirtieron en recurso esencial. Como Alejandro Pizarroso afirma: «La guerra civil española fue banco de pruebas de armamentos y tácticas militares pero también pionera en el terreno de la información y de la propaganda» ${ }^{2}$. Llegado este punto se hace necesario recordar que dado el protagonismo que en la Europa de entreguerras alcanzaron los sistemas totalitarios, el modelo seguido por los contendientes hispanos estuvo en esa línea. Y es que, como Jesús Timoteo Alvarez indica:

«Allí donde logran imponerse tales sistemas totalitarios, que por ser partidistas y fanáticos, por ser espiritualmente, al menos, imperialistas, necesitan llegar a la conciencia de las masas, necesitan el recurso a la propaganda hasta convertirla en la función pública por excelencia, en la columna central del sistema y del Estado» ${ }^{3}$.

2 Ibid. p. 356.

TIMOTEO ÁLVAREZ, Jesús: Historia y modelos de la comunicación en el siglo XX. El nuevo orden informativo. Barcelona, Ariel, 1986, p. 91. 
En esa línea, y para aclarar mejor el concepto se puede reproducir la definición que de propaganda totalitaria hace el teórico norteamericano W.E. Griffith y que puede ser referida al caso aquí estudiado:

«Propaganda totalitaria significa control del pensamiento, a través de la orientación y censura de los medios de comunicación, sometidos a la línea del partido único, a través de la creación de un lenguaje ideológico capaz de conseguir una imagen atractiva y agresiva, a través de campañas científicamente programadas, y con la utilización permanente y planificada de todas las posibles manifestaciones de la inteligencia y la imaginación, que incluyen como elemento eficaz cuanto promueva sentimientos colectivos (temor, odio, pasión, entusiasmo, pie(ad)» .

Aunque ambos bandos recurrieron a sus recursos ${ }^{5}$, nos ceñiremos al que se autodenominó "nacional", porque en él se dieron más claramente los rasgos de totalitarismo y uniformidad antes mencionados.

En este sentido, hay que recordar que, aunque en un principio no existía una ideología concreta y uniforme entre las fuerzas que se sublevan contra la República, las relaciones amistosas con Italia y Alemania, además de con Portugal, inclinaron la balanza hacia unos valores fascistas capitalizados por la Falange. El entramado que surgió de esta unidad entre todos los elementos ideológicos, -capitaneada por los militares en un principio y por Franco más tarde-, en especial a partir de la creación del partido único, fue denominada por la publicistica nacionalista como "Movimiento". En él, el control de la información, la censura y una fuerte propaganda unidireccional, fueron componentes predominantes. Este interés o necesidad de custodia sobre la información se puede observar desde los primeros días y en las primeras órdenes de carácter militar, así como en la incautación de los medios de comunicación de los adversarios. Por ésto no extraña que el 5 de agosto de 1936 se crease el primer organismo para el control de la publicidad por la Junta Técnica de Estado, que fue un Gabinete de Prensa. Y que, según esquemas totalitarios, el anterior fuese transformado días después en Oficina de Prensa y Propaganda. Es una evidencia de cómo ambos elementos fueron

GRIFFITH, W.E., "Comunist propaganda", citado por, Ibíd., p. 93.

Siempre se ha considerado la propaganda republicana como más interesante, y por ello existe una extensa bibliografía. Como ejemplo más conocido de la misma, recordamos la participación del gobierno de 1 República en la Exposición Universal de París de 1937, para la que Picasso pintó el Guernica, quizás la República en la Exposición Universal de París de 1937, para la que Picasso pintó el Guernica, quizás la obra maestra de la propaganda del siglo XX. Nos limitamos aquí pues a remitirnos a algunos ejemplos bibliográficos.Vid. GAMONAL TORRES, Miguel Angel: Arte y politica en la guerra civil española: caso republicano. Granada, Diputación Provincial de Granada, 1987. Del mismo autor: Imagen, propagan da y cultura en la zona republicana durante la guerra civil española. Granada, Universidad de Granada, 1985. HART, Stephen M.: ¡No pasarán! Art, literature in the Spanish Civil War. Londres, Tamesis Books
Ld., 1988. 
considerados paralelos, utilizando la propaganda a la prensa como vehículo para sus necesidades. Conforme avanzó el conflicto, los alzados afianzaron el régimen, especialmente desde que se crea el primer gobierno de Franco en enero de 1938, y los organismos de él dependientes. La propaganda y la información fueron vinculadas al Ministerio del Interior regido por Serrano Suñer quien las desglosó en una Delegación Nacional de Prensa y otra de Propaganda ${ }^{6}$. Se vivió el período de mayor control y totalitarismo en los contenidos y las formas. Como elemento trascendental del proceso actuó la nueva legislación, sobresaliendo la Ley de Prensa el 22 de abril de 1938, basada en el Decreto fascista italiano sobre Prensa, junto con las ideas del ministro alemán de propaganda, Goebbels ${ }^{7}$.

En resumen, como indica la profesora Sara Nuñez del Prado:

«Durante los tres años de guerra, por tanto, el sistema, dirigido desde arriba, se afanó en construir los pilares básicos que justificaran la defensa de la propia contienda como única salida válida a la situación anterior. Y en segundo lugar, se encaminó a una búsqueda diaria de una identidad alternativa de futuro, improvisando toda una teoría de salvación, frente a lo que presentaban como grave crisis nacional y desatino republicano. Para conseguir lo anterior los franquistas utilizaron todos los medios de comunicación a su alcance. De esta forma, prensa, radio, cine, propaganda, teatro, enseñanza, cartelería..., estarían dirigidos y orientados, desde arriba, en aras de conseguir ese fin primordial antes descrito» ${ }^{8}$.

Amparándonos en las afirmaciones anteriores, y para la aproximación al tema, el uso de los derechos humanos como instrumento de propaganda para beneficio del bando nacional, hechos hecho uso de material hemerográfico -especialmente artículos procedentes del $A B C$ de Sevilla, diario que alcanzó gran difusión en la época-, discursos, libros y folletos aparecidos durante el período.

Como es bien sabido, el intento de golpe de Estado por una parte del Ejército el 18 de julio de 1936 y su fracaso posterior significaron el inicio de la guerra civil española. En aquellas circunstancias, por parte de los militares alzados y de las fuerzas que les secundaron, pronto surgió la necesidad de justificar el hecho al objeto de obtener el respaldo de la población y ayuda militar del exterior. Dado que el golpe de Estado se había realizado en contra de un gobierno legitimado en las urnas, en las diversas justificaciones que se improvisaron en los

6 Vid. NUÑEZ DEL PRADO, Sara: Servicios de información y propaganda en la guerra civil española 1936-1939. Madrid, Universidad Complutense, 1992. También PIZARROSO, Opus cit. pp. 361-364.

Vid. SINOVA, Justino: La censura de prensa durante el franquismo. Madrid, Espasa Calpe,1989.

8 NUNEEZ DEL PRADO, Opus cit. pp. 247-8. 
primeros meses ${ }^{9}$, cuando todavía se confiaba en una guerra corta, se esgrimió con fuerza la defensa de España y de los españoles contra las agresiones del gobierno republicano y de los partidos de izquierda que formaban el gobernante Frente Popular.

La prensa de esos primeros meses así lo muestra, con artículos sobre la ilegitimidad de una República que no ha sabido respetar algunos derechos del hombre, y entre ellos el fundamental derecho a la vida. Algo ejemplificado en la muerte del político conservador Calvo Sotelo, a manos de fuerzas del Estado, el 13 de julio en Madrid. Calvo Sotelo se convirtió así en el primer mártir de la guerra, o más exactamente según la terminología de la época, en el protomártir. El mismo Franco, en un discurso radiado el 18 de julio de 1937 con ocasión del primer aniversario del alzamiento dijo:

«Este crimen de Estado conmovió a España; no cabían las sumisiones, acatamientos, ni esperanzas. La revolución comunista, fomentada desde las alturas del Poder, había estallado, y el Ejército, haciéndose intérprete del sentir de todos los españoles honrados, en cumplimiento de su sagrado deber para Dios y para España, decidió lanzarse a su salvación. (...) El Ejército, secundado por el pueblo y las milicias, se alzó contra un Gobierno anticonstitucional, tiránico y fraudulento, y cumpliendo lo que preceptúa nuestra ley constitutiva castrense, se erige en defensor de la Patria, defendiéndola de sus enemigos exteriores e interiores» ${ }^{10}$.

José $\mathrm{M}^{\mathrm{a}}$ Pemán había sido uno de los primeros en dar el título de mártir a Calvo Sotelo. Fue el mismo día de su muerte en un artículo que, por su dureza, se censuró entonces pues era un llamamiento a las armas. Aquel texto vio la luz en octubre de 1936:

«España, la verdadera España -no esa cosa oficial que usurpa su nombre, tiene desde ayer un mártir. De esto, del mártir de España que es desde ayer Calvo Sotelo, no hay nada que decir. Primero, porque no es permitido. Segundo, porque todo lo dice con su propia e incomparable elocuencia el mismo hecho brutal. De eso no hay nada que decir: ¡Hay mucho que hacer! ¡Y por Dios y por Santiago que se hará!» ${ }^{11}$

9 Esa fue la respuesta de unos sublevados que, en el momento de atacar al gobierno republicano, no tenían unas ideas claras sobre la ideología de su propio "Movimiento", y que sólo estaban de acuerdo en su antipatía por el gobierno y sus actitudes. Vid. AROSTEGUI, Julio: "Los componentes sociales y políticos" en La guerra civil española cincuenta años después. Barcelona, Ed. Labor, 1989. p. 48.

10 Obsérvese como descalifica la legitimidad del gobierno republicano y se adjudica para sí la legalidad. Obsérvese como descalifica la legitimidad del gobierno republicano y
Discurso radiado desde Salamanca y publicado en: $A B C, 20-7-37$. p. 4 .

11 Aunque se redactó para Acción Española de Madrid, fue publicado por ABC, 23-10-1936, p. 3. 
En la justificación de la sublevación armada, fue muy airado el atentado a otro derecho fundamental del individuo: el respeto a sus creencias religiosas. La política antirreligiosa de la II República pasó a ser un tema doloroso para la Iglesia católica desde el inicio del régimen. Los católicos españoles se habían sentido perseguidos, y la propaganda del nuevo régimen repitió sin cesar esta injusticia. En un panfleto publicado para la educación de los maestros sobre los orígenes del Movimiento, José Pemartín, uno de sus ideólogos, afirmaba:

«Y aquí pasamos lógicamente al tercer rasgo negativo que provocó nuestro Movimiento: la antirreligiosidad de la República (...) Pero muy pronto el germen satánico y masónico surgió irresistible, y echó llamaradas por las ventanas de doscientos conventos de España aquel tristísimo 11 de mayo ${ }^{12}$; y siguió triunfante al expulsar como un malhechor a esa nobilísima figura del Episcopado español, al santo y egregio cardenal Segura...; y siguieron triunfando la masonería y Satanás, cuando expulsaron a la santa y españolísima Compañía de Jesús a la que por fin hemos tenido la inmensa satisfacción de ver repuesta en su derecho...; y siguió la obra satánica arrancándole nuestras escuelas al Maestro de los maestros, el Crucificado, y suprimiendo la enseñanza de la Religión...» ${ }^{13}$.

Además de las justificaciones para el Alzamiento, cuando el conflicto se transformó en guerra, se hizo necesario mantener la moral propia y atraerse a los que dudaban. En los primeros días, la actitud de los simpatizantes de izquierdas se vio como el inicio de una Revolución que era necesario sofocar. También llegaban noticias de las primeras matanzas, -del enemigo, pues las propias se silencianban-. Conforme se iban "liberando pueblos" aparecían las crónicas de los terribles sucesos de los que eran culpables los "monstruos rojos". Sirva el siguiente artículo del periodista de $A B C$ López Prudencio sobre un pueblo en Extremadura:

«En la vorágine de horrores que han padecido nuestros pueblos hasta la llegada del Ejército libertador destacan los refinamientos de crueldad que las hordas marxistas han empleado con los niños. Las fuerzas libertadoras han encontrado pueblos casi desiertos, y en las casas, sombríamente silenciosas, niños asesinados al lado de los cadáveres de sus madres. Han sido violadas niñas de ocho, de seis años... En un pueblo que no quiero nombrar, por no contribuir a que

12 El día anterior hubo un enfrentamiento en Madrid con un grupo de monárquicos, y al día siguiente, las multitudes se echaron a la calle en toda España quemando numerosos edificios religiosos.

13 PEMARTíN SANJUAN, José: Los orígenes del Movimiento. Burgos, Hijos de Santiago Rodríguez, 1938. p.13 
el baldón se perpetúe, fue violada una niña de cuatro años y abierto después su vientre para sacar las entrañas; y, culmina sobre estas visiones de espanto la de aquel niñito de tres años, fusilado con sus padres, abrazado fuertemente a un juguete infantil, su ilusión candorosa...».

El artículo terminaba con la siguiente afirmación:

«España por fortuna lo sabe. Su ejército glorioso lo está demostrando heroicamente y cumple la misión ecuménica de libertar al mundo de esta pesadilla» ${ }^{14}$.

Estas crónicas de terribles matanzas fueron las que inflamaron los odios y las venganzas. Uno de los documentos más sorprendentes en aquellos días de la propaganda sublevada, y de gran efectividad, fueron las charlas de Queipo de Llano desde Unión Radio Sevilla. En ella destinó gran espacio a contar detalladamente los crímenes de "los rojos" en los pueblos andaluces, en explicaciones semejantes o más terribles que las del artículo antes transcrito. Aunque, a veces, sus historias fueran poco veraces ${ }^{15}$, muchos las dieron por ciertas. Indudablemente, algunos párrafos eran espeluznantes, como ejemplo hemos elegido una parte de su charla del 15 de agosto de 1936.

«Voy a citar algunos de los horrendos crímenes que vienen cometiendo las canallas marxistas, que hacen poner los pelos de punta a los hombres más templados. En Utrera, a un padre le ataron los pies y manos a una silla, y después de rociar de gasolina a sus hijos, les prendieron fuego. No he de deciros el martirio de este pobre padre que presenciaba los horribles sufrimientos de sus hijos y no podía a acudir en su auxilio. A una señora le introdujeron algodones empapados de gasolina en sus huecos naturales y después les prendieron fuego. En Baeza,a

14 LÓPEZ PRUDENCIO, J.: España lo sabe. En: $A B C$, 6-10-1936. p. 3. El tono empleado muestra el nive de ensañamiento al que llegó la propaganda. Aunque las matanzas de gentes de derechas existieron en toda la geografía republicana, las represalias de los nacionales no fueron menos terribles. En Extremadura ocurrió uno de los hechos más vergonzosos de la guerra que fue la matanza de la plaza de toros de Badajoz de la que existen numerosas versiones, una de ellas habla del asesinato de 1800 milicianos, aunque segú Hugh Thomas la cifra nunca se sepa y sea posiblemente menos.Vid. THOMAS, Hugh: La guerra civil española. Barcelona, Grijalbo Mondadori, 1995. pp. 405-407.

15 Antonio Bahamonde, fue delegado de prensa y propaganda con Queipo de Llano el primer año de la guerra, hasta que desertó. En un libro publicado un año después contó cómo la mayor parte de los crímenes fueron inventados para la propaganda por el propio general. Aunque, hay que tener en cuenta que su libro inventados para la propaganda por el propio general. Aunque, hay que tener en cuentá que su libro se convirtió en propaganda para el otro bando, con lo cuas ha que pone: Un añ con Queipo. Memorias de un nacionalista. Barcelona, Ediciones Españolas, 1938. 
una madre próxima a dar luz, le abrieron el vientre, extrajeron la criatura y la cortan por la mitad, en su presencia. A un joven fascista le seccionaron ambas piernas y un brazo y luego le fusilaron. A otro le cortaron las dos piernas y después lo remataron bárbaramente. A un sacerdote le abrieron el intestino y luego se lo llenaron de cal viva» ${ }^{16}$.

Sin embargo, el propósito de Queipo era emplear los ataques a los derechos humanos del enemigo, para excusar la represión ejercida, con gran violencia en su caso, algo que él mismo dejó ver en sus palabras:

«Como en Arahal, hubo en Morón un grupo de hombres ciegos que ha cometido salvajadas sin ejemplo, atropellando a personas de derechas que no se habían metido con ellos. Y tengo noticias de que en varios pueblos tienen los marxistas prisioneros de derechas, con los que piensan hacer parecidas barbaridades. A todos les recuerdo que, por cada persona honrada que muera, yo fusilaré, por lo menos diez; y hay pueblos donde hemos rebasado esta cifra. Y no esperen los dirigentes salvarse, apelando a la fuga pues los sacaré de bajo de la tierra, si es preciso, para que se cumpla la ley» ${ }^{17}$.

No todos los relatos fueron tan crudos, pero sí muy frecuentes y numerosos. Se hicieron habituales los escritos por personas huidas de la "zona roja" en libros o en periódicos. Obras como Mis dos meses de prisión en Málaga, del padre Francisco García Alonso;Soy un fugitivo, de Romero-Marchent; Últimos días en la cárcel modelo de Leopoldo Nunes; Como fui ejecutado en Madrid, de Jacinto Miquelarena; Presos de los rojo-separatistas, de Federico Casara; y un largo etcétera, siguen en la tónica de culpar al bando republicano y a los partidos de izquierdas de actos terribles contra los derechos humanos. Pero también coinciden en la denuncia de la destrucción que de España están llevando a cabo, como otra medida deslegitimadora. Y por supuesto no se olvidan nunca estos refugiados de sus ciudades. Es muy significativo ver en un periódico como $A B C$, que ha perdido su sede madrileña y acoge en la sevillana a los periodistas huidos de la capital, el gran acopio de títulos sobre los padecimientos de Madrid. Un ejemplo puede ser el del redactor de la sede madrileña Juan Deportista, -seudónimo de Alberto Martín Fernández-, quien publica una columna bajo el título: Madrid bajo el fantasma rojo, durante los últimos meses de 1936. Cuando Jacinto Miquelarena huye de Madrid, redacta durante unos meses una columna bajo el nombre $\mathrm{Ha}$ llegado el fugitivo, de semejantes características. Durante toda la contienda los

6 GIBSON, Ian: Queipo de Llano, verano de 1936. (Con las charlas radiofónicas completas). Barcelona, Grijalbo, 1986.p. 118 17 Ibíd. p. 185 
testimonios sobre la situación en la otra zona y la destrucción en la que se encuentran las ciudades liberadas destruidas por sus ocupantes antes de abandonarlas son innumerables.

Aquí nos gustaría traer el ejemplo de lo que se dijo sobre lo ocurrido en Guernica. Ciertamente, en muchos casos la destrucción de las ciudades se debían no sólo a la guerra, sino a la saña de los republicanos más extremistas en especial contra los edificios religiosos, a lo que dedicaremos a continuación unas palabras. En el caso de Guernica sin embargo, la destrucción total de la pequeña ciudad se debió al bombardeo de la Aviación alemana. Fue un hecho que conmocionó al mundo, pues era la primera vez que se se empleaban aviones contra un objetivo no militar, y también por la brutalidad demostrada en destruir la urbe, tan simbólica para el nacionalismo vasco. De sobra es conocido que Picasso, quien se encontraba proyectando su participación en el pabellón español de la Exposición Internacional de París, eligió este tema para una de las obras artísticas más famosas de este siglo. Pues bien, este atentado contra los derechos humanos, tan impactante a nivel internacional, fue explicado de forma opuesta en numerosos artículos y folletos en los que se culpaba a las tropas republicanas vascas de causar la destrucción antes de su huida. Victor de la Serna escribió en $A B C$ :

«Son los separatistas los que han incendiado Guernica, con una morbosa perversidad de sacrílegos. (...) Ellos habrán reído satánicamente detrás de las cumbres, en su huida, mientras estallaba el artefacto que había de reventar, entre acres nubes de pólvora, las últimas casas de la villa. Aún he alcanzado a ver los cables que unían las minas colocadas por los masoncitos entre sacrílegas bendiciones de los clérigos renegados» ${ }^{18}$.

Este hecho nos demuestra la manipulación de la propaganda. Y el anterior es sólo uno de los innumerables casos que se dieron en nuestra guerra civil -y que se dan en todas las guerras-. Sin embargo, es necesario aclarar que, normalmente, los ataques contra el enemigo no se extendieron a todo el pueblo. La población de la zona republicana fue presentada como víctima que necesitaba ser liberada, los culpables eran el gobierno y los partidos y sindicatos de izquierda. De cara al interior, especialmente en la propaganda que se hacía en los frentes, se les conminaba a cambiar de bando, y se intentaba trocar la imagen terrible que del fascismo y la España nacional se tenía entre ellos, asegurando que era el resultado de la mentira de la propaganda republicana...

18 DE LA SERNA, Víctor: Signos. Guernica. ABC, 19-5-1937. pp. 3-4. Sobre el tema del bombardeo de Guernica y la propaganda franquista recomendamos: SOUTHWORTH, Herbert: La destrucción de Guernica, Periodismo, diplomacia, propaganda e historia. París, Ruedo Ibérico, 1977. 
«Ahora bien, no es este el aspecto más canallesco de su propaganda sino aquel que, a fuerza de mentiras, trata de arraigar en el ánimo de los españoles equivocados que todavía con ellos, el convencimiento de que, seguir allí, es el único medio de prolongar la vida. A los dirigentes de esa campaña miserable que sacrifica en falsedades tantas vidas españolas, les consta muy bien que en nuestro campo no se asesina vilmente como en el suyo, ni se mata a nadie que, por voluntad o azar, se pase a nuestra zona, so pena que venga con las manos manchadas de crímenes imperdonables. Y así, a fuerza de mentira y de terror, logran sostener en pie un Ejército de españoles engañados, temerosos del látigo soviético que les esclaviza» ${ }^{19}$.

Claro queda en este texto, que, de cara al interior, la vida en la España de Franco carecía de todos los defectos que se achacaban al contrario. Se alababa la nueva legislación social que el régimen estaba promulgando de cara a los trabajadores, -Fuero del Trabajo-, e incluso, se multaba con grandes sumas a los empresarios que no la cumplían. Mas, toda la propaganda no podía acallar las noticias sobre fusilamientos, y persecuciones, realizados legalmente desde la Ley de Responsabilidades Políticas promulgada el 9 de febrero de 1939.

Un aspecto en el que, no obstante, toda la propaganda se mostró unánime dentro y fuera de nuestras fronteras fue el de la persecución de la Religión en el territorio republicano. El tradicional odio contra la Iglesia católica por parte de las izquierdas se volvió especialmente violento desde que se conoció el Alzamiento de los militares en Marruecos. En Sevilla en los días 18 y 19 de julio se quemaron 16 iglesias $^{20}$. No sólo el patrimonio nacional se vio afectado; religiosos y religiosas sufrieron un terrible hostigamiento en la mayor parte de la España republicana, -un caso aparte lo constituyó el País Vasco-. Los asesinatos de sacerdotes y monjas fueron una de las propagandas más eficaces de los nacionales. En efecto, en el exterior fue la más poderosa, -junto al miedo a una revolución bolchevique al sur de Europa-, atrayendo las simpatías de la mayoría de los católicos del mundo. Además, la jerarquía eclesiástica apoyó abiertamente al bando nacional desde el principio, siendo ese respaldo el que permitió a la propaganda franquista convertir a la guerra en Cruzada. Como indica Angel Viñas: «La guerra incumbía,

19 BONMATI DE CODECIDO, F: La propaganda de las palabras y los hechos. En:ABC, 7-5-1937. p. 4 20 Estas fueron: Santa Ana, San Bernardo, los Dolores, San Gil, la Inmaculada Concepción, San Juan de la Palma, San Julián, San Marcos, Santa Marina, las Mercedarias, Monte Sión, O, Omnium Sanctorum, San Román, San Roque y las Salesas Sobre las pérdidas sufridas en estos días véase el libro de HERNÁNDEZ Román, San Roque y las Salesas Sobre las pérdidas sufridas en estos días véase el libro de HERNANDEZ
DÍAZ Y SANCHO CORBACHO: Estudio de los edificios religiosos y objetos de culto de la ciudad de Sevilla saqueados y destruidos por los marxistas. Tomo I, Sevilla 1937. 
así a todos los católicos. Era una guerra santa, de dimensiones universales. Favoreció, en consecuencia, el activismo católico en el plano internacional» ${ }^{21}$.

De cara al interior, el martirio de religiosos se unió a las terribles historias de la zona roja. En enero de 1937 el obispo de Córdoba publicaba una carta en la que dedicaba un recuerdo especial a éstos. El obispo Adolfo Pérez Muñoz escribía:

«Así también estos carísimos sacerdotes han sucumbido, imitando al mártir de la Cruz, Nuestro Señor Jesucristo, pues han muerto perdonando, cuando les era permitido confortaban con exhortaciones piadosas a la triste comitiva que formaban otros, igualmente sentenciados a muerte, abriendo en su alma vivos sentimientos de fe y de inmortales esperanzas» ${ }^{22}$.

Las historias de sacerdotes martirizados y muriendo en actitud heroica sorprendieron al mundo. Se organizó una Oficina Católica de información internacional, que publicó folletos entre los que destacó: Ni somos iguales ni hacemos lo mismo, aparecido en noviembre de 1937. También, medios católicos de otros países publicaron escritos que alcanzaron gran difusión ${ }^{23}$. En este sentido, la mejor publicidad sobrevino con la aparición el 1 de julio de 1937 de la Carta Colectiva del Episcopado español ${ }^{24}$. Provocó que poco después comenzaron a llegar a España adhesiones a favor de la "Cruzada", como la de los arzobispos de París y de Westminster en octubre. Y no se puede negar su vinculación con el reconocimiento informal del gobierno de Burgos por parte del Vaticano el 28 de agosto de ese año. La Iglesia de Roma tardó en hacerlo de forma oficial, porque no todos los católicos eran unánimes en su pensamiento. El caso de los 14 sacerdotes vascos asesinados por sus ideas nacionalistas, o el de las masacres, tristemente ciertas en ambos bandos, hizo que importantes cristianos del mundo, como el filósofo católico francés Jacques Maritain, fuesen críticos con el nuevo régimen. La respuesta de la propaganda franquista, en este caso muy famoso entonces, fue la descalificación de lo que dieron en llamar: La campaña antiespañola del judio Maritain $^{25}$.

21 VIÑAS:, Angel: "Los condicionantes internacionales". En: La guerra civil española, cincuenta años después, Opus cit. pp. 163-164.

22 Publicado en $A B C, 21-1-1937$, p. 16.

23 Fue muy sobresaliente la influencia del folleto, editado por los católicos franceses, sobre El martirio de las obras de arte, número extraordinario de L'lustracition en el que, tras otros números más prorrepublicanos, la revista muestra la destrucción de obras religiosas por los rojos.

24 La Jerarquía católica se mostró casi unánime en su apoyo a los sublevados con las excepción del obispo de Vitoria, Múgica, y del arzobispo de Tarragona, Vidal y Barraquer. Con esas dos excepciones, todos firmaron una carta escrita por el Primado español, cardenal Gomá, a los obispos del mundo en la que
foras afirmaban que la guerra civil era "teológicamente justa".

25 Título de una cuña publicada en $A B C$ el $25-5-1938$, p. 9 . 
De cara al exterior, otros muchos hechos conmovieron a las conciencias internacionales. Sería imposible enumerarlos; el asesinato de grandes intelectuales, la evacuación de refugiados, las matanzas de unos o de otros... etc. La propaganda siempre tenía una explicación. Citemos aquí un par de muestras. Ante el asesinato de Federico García Lorca, Franco, en una entrevista al periodista Sáez Hayes publicada en La Prensa de Buenos Aires y El Mercurio, de Santiago de Chile "aclaraba":

«Se ha hablado mucho en el extranjero de un escritor granadino, el vuelo de cuya fama no puedo yo medir hasta qué fronteras hubiera llegado; se ha hablado mucho porque los rojos han agitado ese nombre como un señuelo de propaganda. Lo cierto es que en los momentos primeros de la revolución en Granada, ese escritor murió mezclado con los revoltosos. Son los accidentes naturales de la guerra. Granada estuvo sitiada durante muchos días y la locura de las autoridades republicanas, repartiendo armas a la gente, dio lugar a chispazos en el interior, en alguno de los cuales perdió la vida el poeta granadino. Como poeta su pérdida ha sido lamentable y la propaganda roja ha hecho pendón de este accidente, explotando la sensibilidad del mundo intelectual. En cambio, esa gente no habla de cómo fueron asesinados friamente, con saña que pone espanto en el ánimo más templado, don José Calvo Sotelo, don Víctor Pradera, don José Polo Benito, el duque de Canalejas, don Honorio Maura, don Francisco Valdés, don Rufino Blanco, don Manuel Bueno, don José María Albiñana; don Ramiro de Maeztu, don Pedro Muñoz Seca, don Pedro Mourlane Michelena, don Antonio Bermúdez Cañete, don Rafael Salazar Alonso, don Alfonso Rodríguez Santamaría, presidente de la Asociación de la Prensa; don Melquiades Alvarez, don Enrique Estévez Ortega, don Federico Salmón, padre Zacarías G. Villadas, don Fernando de la Quadra, don Gregorio de Balparda y tantos otros cuya lista haría interminable estas contestaciones. Queda dicho que no hemos fusilado a ningún poeta» ${ }^{26}$.

El segundo ejemplo podría ser el tema de los refugiados, especialmente, los niños -muchos de ellos vascos- que fueron llevados a otros países -Méjico, la Unión Soviética- con fines humanitarios. Para el régimen franquista ésta fue una de las mayores aberraciones posibles de todas las realizadas por los gubernamentales. El gobierno de Franco llegó a publicar notas de protesta, que fueron alabadas por la prensa en los siguientes términos:

«Nuevamente "exporta" niños a Rusia la España roja. Y nuevamente se protesta desde Burgos de que el mundo continúe impávido ante esta crueldad de

26 Reproducido en $A B C$, 6-1-1938. p. 6. 
tipo perfectamente vengativo. La España macabra del doctor Negrín se presta a todas las experiencias que quiera realizar sobre ella la delirante estupidez soviética, y en estos momentos, por lo visto, Moscú exige más "material" humano, más niños que le permitan llegar a la obtención pura del hijo químicamente huérfano...» 27

Cuando al final de la guerra, miles de españoles cruzaron la frontera hacia Francia, ya no quedaba tristeza para ellos... Y es que, conforme se aproximaba la victoria cambió la actitud. Ya los crímenes de los rojos no servían para seguir atacándoles, puesto que se les estaba venciendo, sino para no ser condescendientes y perdonarles, para intentar aplastarlos y no firmar una paz pactada, para aniquilarlos incluso. Ello es más patente desde que los republicanos pierden la batalla del Ebro y comienza la conquista de Cataluña. Ante la situación, el propio gobierno republicano intentó, con mediación internacional, conseguir una tregua y un armisticio, en un momento en el que, tras la ocupación de Checoslovaquia por Alemania, existía la posibilidad de una guerra europea que les beneficiaría. La respuesta oficial del gobierno de Franco fue rotunda: «no aceptará jamás como fin de la guerra otra solución que no sea la rendición sin condiciones del enemigo» ${ }^{28}$.

Cuando las victorias y conquistas de ciudades se hizo imparable, desde la seguridad de la victoria, surgieron otras voces y otras prioridades. En primer lugar se oyeron voces demandando la no compasión con los vencidos. O se culpó a los rojos de tener una actitud equivocada:

«Ya que los rojos carezcan de otros méritos que ostentar, en último caso podrán enorgullecerse de haber retardado hasta lo inverosímil el momento de morir. (...) Después del descalabro de Cataluña todo el mundo suponía, con arreglo a la lógica, que la rendición total había de ser inmediata; pero el espécimen rojo tiene sin duda una lógica distinta, y la del rojo español se diferencia todavía más que otra alguna» ${ }^{29}$.

La respuesta dada a toda posible mediación fue explícita dado el abismo existente entre ambos contendientes:

«Pero hay algo que nos separa con dimensión de abismo de las causas y de las figuras operantes en el proceso de la disolución de España: su traición a la unidad y al Destino de la Patria, sus expresos vasallajes a la dictadura soviética que los manda y, finalmente, en estos tres años últimos, sus crímenes infrahuma-

MIQUELARENA, J: La exportación de generaciones. ABC, 11-12-1938. pp. 4-5.

Nota del Gobierno nacional. ABC, 5-6-1938, p. 9 .

29 SALAVERRÍA, José Mª: La fea y lamentable agonía. ABC, 19-3-1939. p.3. 
nos y el desastre inenarrable de su ferocidad de delincuentes comunes contra el honor, la vida y la propiedad de los españoles.

Ese abismo no hay pacto, ni hay mediación que lo salve jamás. Ese abismo está abierto de una manera irreparable. A un lado quedan los victimarios y verdugos; al otro, es decir, al nuestro, queda el espíritu y la gloria invictos de los soldados, cohesionados con el de todos los demás supervivientes de la hecatombe. Y con nosotros, dándonos aliento, si es que nos faltase, comunicándonos bravura en la acción y fortaleza para la memoria y decisión en el propósito irrevocable de justicia serena, nuestros millares de muertos de la guerra y de la revolución de la anteguerra y de la anterrevolución que están presentes en nuestros afanes como la inmortalidad de España.

No hay mediación que pueda salvar el abismo entre las víctimas y sus verdugos» $»^{30}$.

A fin de cuentas, no sólo se vencía en la guerra civil, España se convirtió en la salvadora de la civilización occidental y europea frente a la barbarie asiática representada en las teorías marxistas y bolcheviques procedentes de Rusia. Esta será la propaganda que continúe durante la primera parte del franquismo.

Llegados aquí sólo nos resta decir que el número de ejemplos sobre el tema puede multiplicarse hasta la saciedad, lo que demuestra su trascendencia. Un aspecto de gran interés como todos los relacionados con la historia de la propaganda de los años treinta. Creemos que las especiales características de la Guerra civil española, que todavía provocan gran expectacuón, y de la propaganda totalitaria que en ella se practica, pueden resultar de interés. Sirvan los ejemplos precedentes para completar el estudio de la propaganda en nuestro siglo y en nuestra guerra civil.

30 Cuña propagandística inserta en la prensa el 15 de octubre de 1938. Se repitieron numerosas cuñas en todos los diarios a partir de esas fechas de semejante contenido. 